\title{
Hepatic lesions in a redstriped rockfish (Sebastes proriger) suggestive of a herpesvirus infection
}

\author{
M. L. Kent ${ }^{1, *}$, M. S. Myers ${ }^{2}$ \\ ${ }^{1}$ Center for Salmon Disease Research, Department of Microbiology, 220 Nash Hall, Corvallis, Oregon 97331-3804, USA \\ ${ }^{2}$ Environmental Conservation Division, Northwest and Alaska Fisheries Center, National Marine Fisheries Service, \\ National Oceanic and Atmospheric Administration, 2725 Montlake Blvd. E, Seatlle, Washington 98112, USA
}

\begin{abstract}
Unusual lesions were observed in a redstriped rockfish (Sebastes proriger) collected during a survey of marine fishes off the coast of British Columbia, Canada. This particular fish exhibited prominent hepatomegaly, with large, coalescing, multiple hemorrhages. The affected liver exhibited remarkable histological changes that, taken together, strongly suggested infection by a virus of the herpesvirus group. Multiple, multinucleated giant cells or syncytia of hepatocytes occurred throughout the liver and were associated with massive, coalescing areas of coagulation necrosis, edema, congestion and cavernous hemorrhages (peliosis hepatis) with thrombosis. In addition, the liver showed multifocal inflammation, characterized by perivascular and peribiliary cuffing of mononuclear inflammatory cells. High magnification of the syncytia revealed that the nuclei were pleomorphic, hyperchromatic, and typically contained eosinophilic to densely amphophilic inclusion bodies of varying size, closely resembling Cowdry Type A inclusions. These inclusions stained red to purple in Feulgen's stain, indicating presence of DNA. Electron-lucent spheres $(-100 \mathrm{~nm}$ diameter $)$ were observed within hepatocyte nuclei by transmission electron microscopy, suggestive of herpesvirus capsids. To our knowledge, this is the first report of a putative or confirmed herpesvirus infection in any rockfish of the genus Sebastes.
\end{abstract}

KEY WORDS: Herpesvirus · Rockfish - Liver lesions

Herpesviruses (family Herpesviridae) are well recognised pathogens of captive and wild marine and freshwater fishes. To date, at least 20 herpesviruses have been described from a wide taxonomic host range of fishes (Wolf 1988, Hedrick \& Sano 1989, Hetrick \& Hedrick 1993). Many are epitheliotropic and are associated with skin lesions (e.g., Pacific cod herpesvirus, pike herpesvirus, walleye herpesvirus, shark

•E-mail: kentm@orst.edu herpesvirus, sheatfish herpesvirus, smelt papilloma herpesvirus, turbot herpesvirus, Herpesvirus cyprini), whereas others cause systemic disease (e.g., channel catfish virus, Herpesvirus salmonis, Oncorhynchus masou virus) (Wolf 1988, Hetrick \& Hedrick 1993). Cells infected with several viruses of this family exhibit typical, amphophilic to eosinophilic intranuclear inclusion bodies (Cowdry Type A inclusions), surrounded by an artifactual halo, that possess demonstrable DNA by the Feulgen stain (Roizman 1982, Von Lichtenberg 1984). Some, such as Herpesvirus salmonis, the closely-related steelhead herpesvirus, the turbot herpesvirus, and other herpesviruses infecting mammalian hosts, cause syncytia or multinucleated giant cell formation, along with coagulative necrosis, edema, and associated hemorrhage in internal organs such as the liver and pancreas (Strano 1976, Wolf \& Smith 1981, Von Lichtenberg 1984, Wolf 1988, Eaton et al. 1989).

As part of an ongoing survey of diseases in wild marine fishes of British Columbia, Canada, we observed remarkable liver lesions in 1 of 36 redstriped rockfish (Sebastes proriger) collected off the coast of Vancouver Island lat. $51^{\circ} 20.2^{\prime} \mathrm{N}$, long. $129^{\circ} 33.7^{\prime} \mathrm{W}$ on 24 August 1996. A variety of fish species were collected by otter trawl and necropsied on board the research vessel 'W.E. Ricker'. This particular fish exhibited prominent hepatomegaly, with large, coalescing, multiple hemorrhages, while other internal organs, gills and integument appeared normal. The liver, other internal organs, and gills were preserved in Davidson's fixative for histological analysis. Tissues were prepared using standard histological methods and sections were stained with either Harris' hematoxylin and eosin or Feulgen's nuclear stain for DNA (Preece 1972). Liver tissue that had been preserved in 


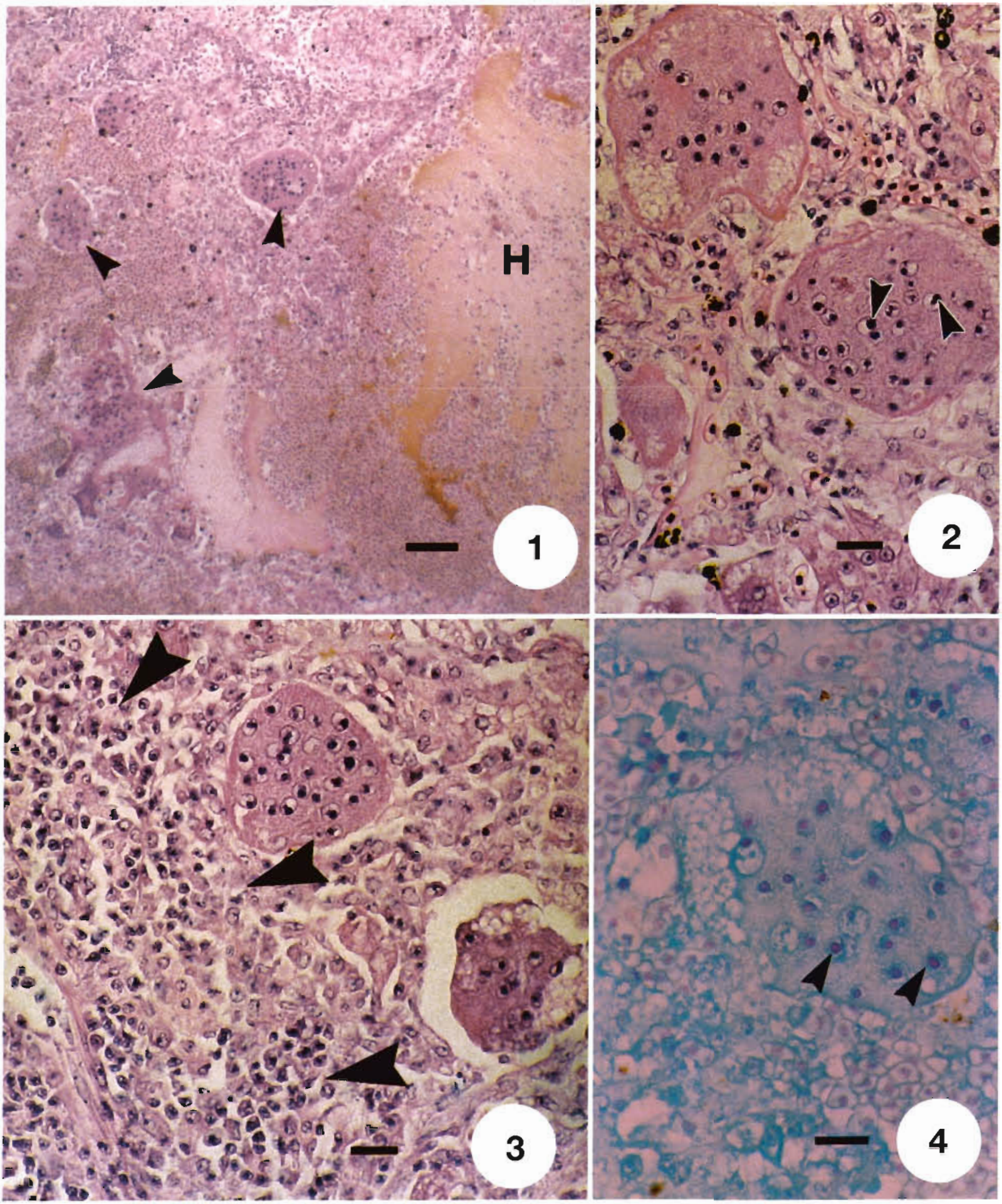

Figs. 1 to 4. Sebastes proriger. Severely necrotic and hemorrhagic liver infected with putative herpes infection. Fig. 1. Low magnification showing hepatocellular syncytia or multinucleated giant cells (arrowheads) in areas of liver exhibiting necrosis, edema, hemorrhage, and thrombosis. Note that the architecture of the liver is completely disrupted. $H=$ hemorrhage. H\&E stain. Scale bar $=50 \mu \mathrm{m}$. Fig. 2. Hepatocellular syncytia or multinucleated giant cells with densely amphophilic intranuclear inclusions (arrowheads). H\&E stain. Scale bar $=10 \mu \mathrm{m}$. Fig. 3 . Hepatocellular syncytia or multinucleated giant cells in area of liver also showing perivascular inflammation (demarcated by arrowheads). H\&E stain. Scale bar $=20 \mu m$. Fig. 4 . Feulgen-positive inclusions (arrowheads) in nuclei of hepatocellular syncytia or multinucleated giant cells. Feulgen nuclear stain for DNA. Scale bar $=20 \mu \mathrm{m}$ 


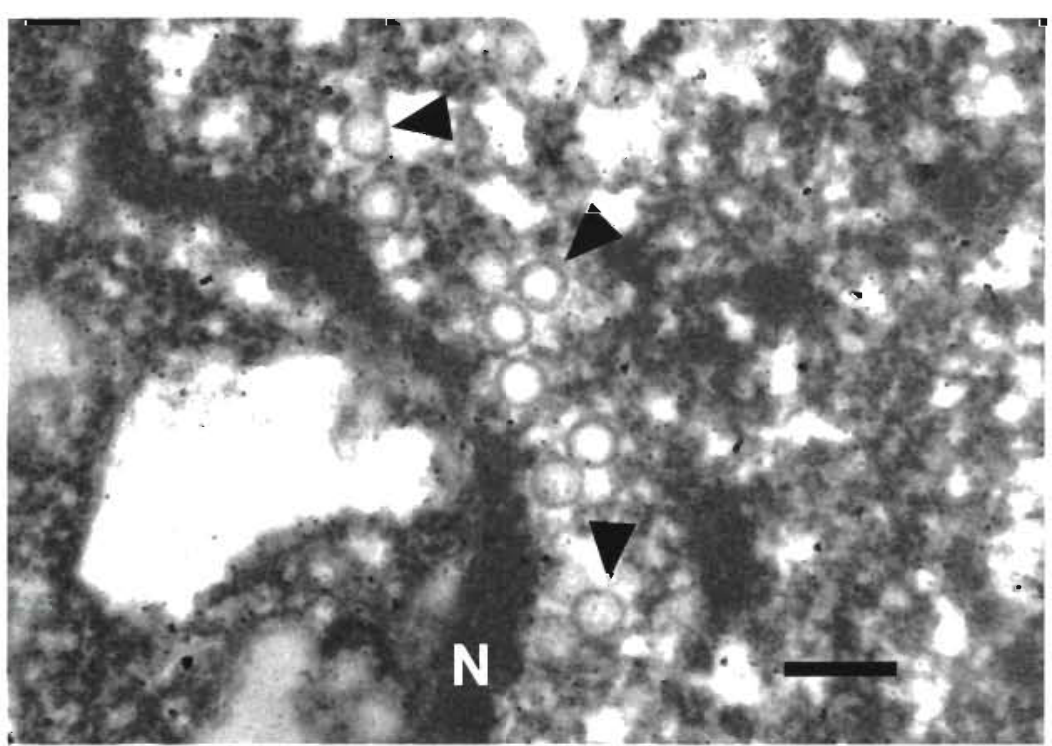

Fig. 5. Sebastes proriger. Transmission electron micrograph of hepatocyte nucleus containing putative herpesvirus capsids (arrowheads). $\mathrm{N}=$ nuclear membrane. Scale bar $=200 \mathrm{~nm}$

Davidson's solution was also re-processed for transmission electron microscopy using standard methods.

The affected liver exhibited remarkable histological changes (Figs. 1 to 4 ) that, taken together, strongly suggested infection by a virus of the herpesvirus group. Multiple, multinucleated giant cells or syncytia of hepatocytes occurred throughout the liver and were associated with massive, coalescing areas of coagulation necrosis, edema, congestion and cavernous hemorrhages (peliosis hepatis) with thrombosis (Fig. 1). In addition, the liver showed multifocal inflammation, characterized by perivascular and peribiliary cuffing of mononuclear inflammatory cells (Fig. 3). High magnification of the multinucleate giant cells or syncytia (Figs. 2 to 4 ) revealed that the nuclei were pleomorphic, hyperchromatic, and typically contained eosinophilic to densely amphophilic inclusion bodies of varying size, closely resembling Cowdry Type A inclusions. These stained red to purple in Feulgen's stain, indicating presence of DNA (Fig. 4). The other internal organs examined (kidney, heart, intestinal tract, exocrine pancreas) and gill exhibited no significant histopathological changes.

The ultrastructural integrity of the liver sample processed for transmission electron microscopy was poor, typical of Davidson's-preserved tissues. However, electron-lucent spheres ( $100 \mathrm{~nm}$ diameter) were observed within hepatocyte nuclei (Fig. 5).

Editorial responsibility; Jo-Ann Leong,

Corvallis, Oregon, USA
The formation of syncytia or multinucleate giant cells are a hallmark of infections by some herpesviruses, and occur in both in vivo infections in vertebrates and in infected cell cultures (Strano 1976, Jawetz et al. 1982, Roizman 1982, Von Lichtenberg 1984, Wolf 1988). Therefore, hepatic lesions observed in the rockfish, especially the occurrence of hepatocellular syncytia or multinucleated giant cells with Feulgen-positive Cowdry Type A intranuclear inclusion bodies, are consistent with a herpesvirus infection. In addition, although the liver tissue examined by transmission electron microscopy was suboptimally preserved, we detected intranuclear particles consistent in size and shape with herpesvirus capsids. To our knowledge, this is the first report of a putative or confirmed herpesvirus infection in any rockfish of the genus Sebastes.

\section{LITERATURE CITED}

Eaton WD, Wingfield WH, Hedrick RP (1989) Prevalence and experimental transmission of the steelhead herpesvirus in salmonid fishes. Dis Aquat Org 7:23-30

Hedrick RP, Sano T (1989). Herpesviruses of fishes. In: Ahne W, Kurstak E (eds) Viruses of lower vertebrates. SpringerVerlag, Berlin, p 161-170

Hetrick FM, Hedrick RP (1993) New viruses described in finfish from 1988-1992. Annu Rev Fish Dis 3:187-207

Jawetz. E, Melnick JL, Adelberg EA (1982) Review of medical microbiology, 15th edn. Lange Medical Publications, Los Altos, CA, p 553

Preece A (1972) A manual for histologic technicians. Little, Brown and Company, Boston

Roizman B (1982) The family Herpesviridae. General description, taxonomy, and classification. In: Roizman B (ed) The viruses, Vol 1. Herpesviruses. Plenum Press, New York, p $1-23$

Strano AJ (1976) Viral pneumonias; Herpes Group exanthemas. In: Binford $\mathrm{CH}$, Connor DH (eds) Pathology of tropical and extraordinary diseases, Vol 1 . Armed Forces Institute of Pathology, Washington, DC, p 68-73

Von Lichtenberg F (1984) Infectious diseases; viral, chlamydial, rickettsial, and bacterial diseases. In: Robbins SL, Cotran RS, Kumar V (eds) Pathologic basis of disease. WB Saunders Co, Philadelphia, p 273-350

Wolf K (1988) Fish viruses and fish viral diseases. Comstock Publishing Associates, Cornell University Press. Ithaca, NY

Wolf K, Smith CE (1981) Herpesvirus salmonis: pathological changes in parenterally-infected rainbow trout, Salmo gairdneri Richardson, fry. J Fish Dis 4:445-457

Submitted: May 3, 1999; Accepted: December 8, 1999

Proofs received from author(s): June 15, 2000 